\title{
Management of Egg Bound and Oviductal Prolapse in Duck
}

\author{
Laishram Kipjen Singh ${ }^{1 *}$, W. Pipelu ${ }^{2}$, G.K. Mishra ${ }^{1}$, Nitish Kharayat ${ }^{1}$, \\ M.K. Patra ${ }^{1}$, S.K. Singh ${ }^{1}$ and H. Kumar ${ }^{1}$ \\ ${ }^{1}$ Animal Reproduction Division, ${ }^{2}$ Division of Veterinary Surgery, ICAR-Indian Veterinary \\ Research Institute, Izatnagar- 243122, U.P., India \\ *Corresponding author
}

\section{A B S T R A C T}

\section{Keywords}

Duck, Egg bound,

Cloaca, Vent,

Potassium

permanganate,

Lignocaine

Article Info

Accepted:

26 October 2017

Available Online:

10 November 2017
A two year old female duck was presented to the Referral Veterinary Polyclinic, VGO, IVRI, Izatnagar, U.P. with history of Egg bound and oviduct prolapse for past $6 \mathrm{hrs}$ (i.e. 6 o'clock in the early morning). Close examination revealed necrosed area of the lower part of oviduct protruded from the vent and retained egg inside the prolapsed mass. Prolapsed mass was washed with $0.1 \%$ potassium permanganate solution. Lignocaine $2 \%$ gel was applied over the prolapsed part. The retained egg was gently removed through the cloacal orifice. Ice cold pack was applied over the prolapsed area along with purse string suture pattern around the circumference of the vent, allowing the egg to fit through.

\section{Introduction}

Egg bound is a serious disorder condition that mostly affects young layers in which the egg is lodged in cloaca but not laid (Crespo et al, 2003). Obstruction of oviduct or uterus by an egg is a common problem seen mainly in young female birds at the initial stage of laying period (Joy and Devia, 2014).

It occurs secondary to any condition that causes chronic, excessive straining such as normal physiologic hyperplasia egg laying. Female ducks which lay abnormally large or abnormal shape eggs are at higher risk for developing this condition. The present paper describes a case of egg bound and its management aspect.

\section{Materials and Methods}

A two year old female duck was presented to the Referral Veterinary Polyclinic, VGO, IVRI, Izatnagar, U.P. with history of Egg bound and oviduct prolapse for past $6 \mathrm{hrs}$ (i.e. 6 o'clock in the early morning) (Fig. 1). The bird had started laying egg for the past 4 days. The bird was anorectic and depressed. On close examination, necrosed area of the lower part of the oviduct protrudes from the vent and retained egg inside the prolapsed mass was observed (Fig. 2).

\section{Results and Discussion}

The prolapsed mass was washed with $0.1 \%$ Potassium permanganate solution to prevent 
against desiccation and foreign particles contamination. After washing the prolapsed part further contamination was prevented by avoiding the bird to lay down on the ground and by keeping on clean drapes. Lignocaine $2 \%$ gel was applied over the prolapsed part to avoid straining and to produce anaesthetizing effect, followed by lubricating the area with mineral oil in order to keep moist and give best result. The retained egg inside the prolapsed tissue was gently removed through cloacal opening without breaking inside, otherwise it might cause allergic reaction and contamination. Ice cold pack was applied over the prolapsed area to help shrink the swollen tissue. After about 10 minutes the reduced swollen mass was pushed back inside the vent.
Fig.1 Prolpase of uterus

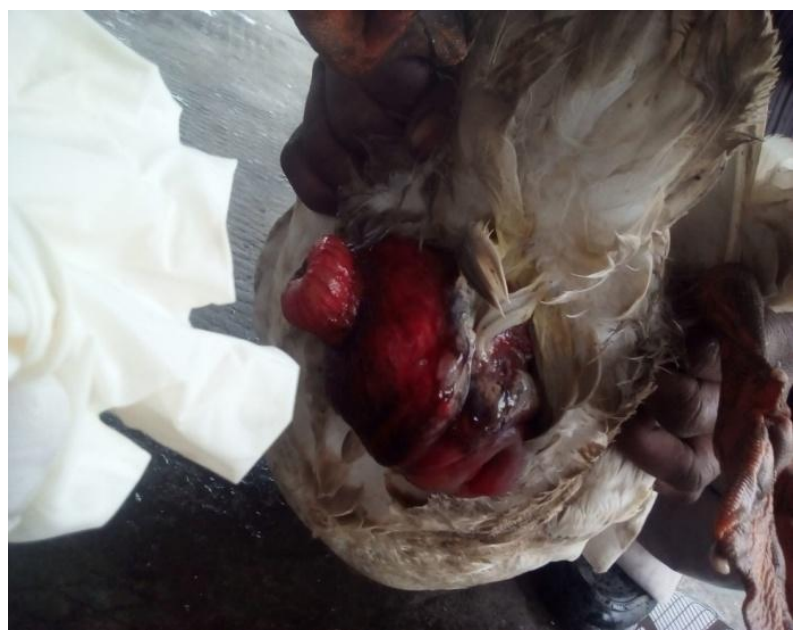

Fig.2 Necrosed part of uterus and egg bound

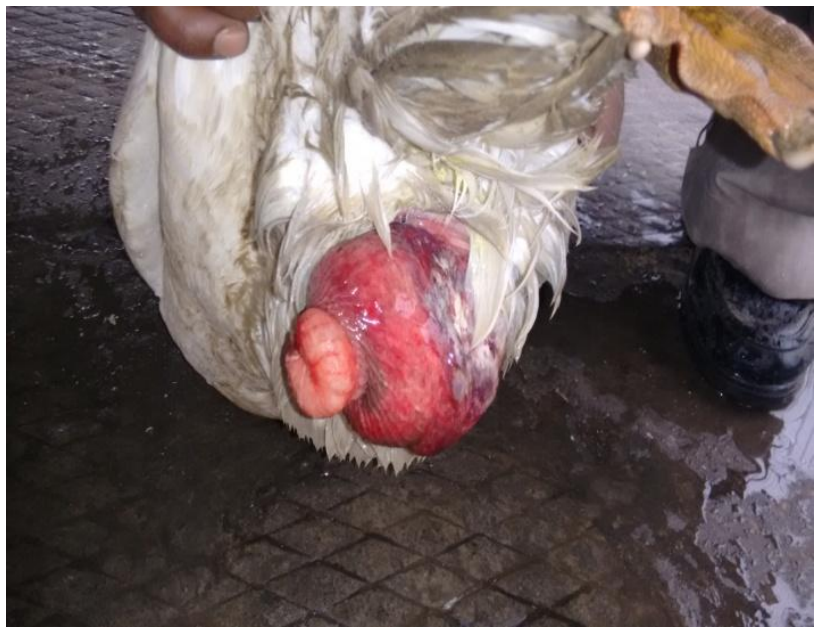

Fig.3 After removal of egg and application of suture

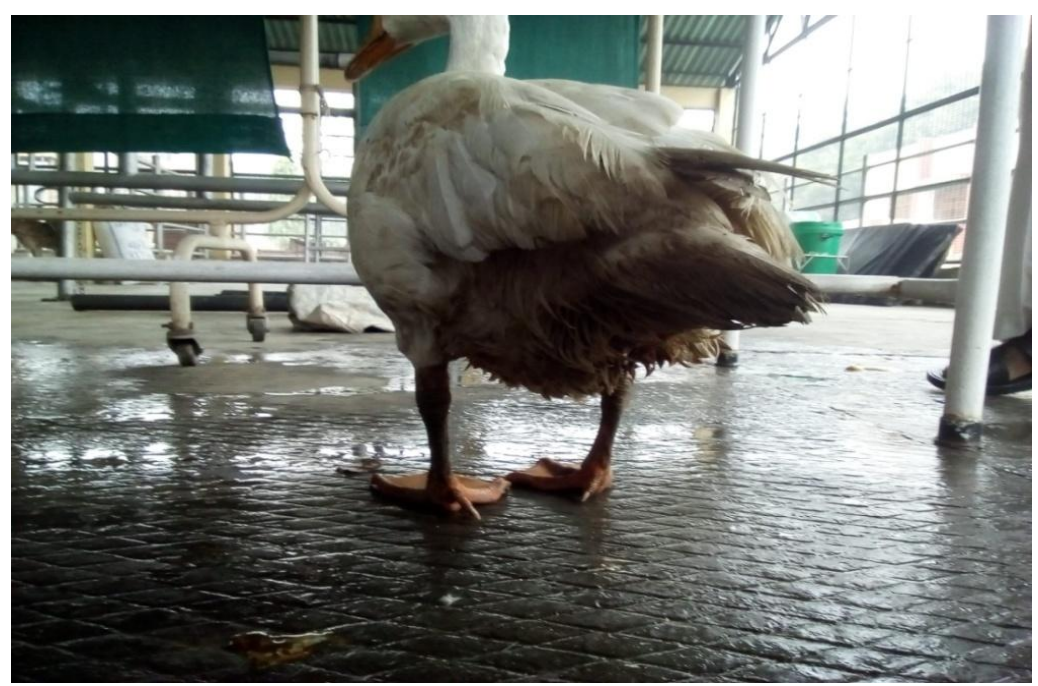


Purse string suture pattern was applied around the circumference of the vent using black braided silk, allowing the egg to fit through (Fig.3). The owner was advised to remove the suture after few hours. Postoperatively antibiotic Enrofloxacin was given @ 10 mg/kg body weight for 5 days along with oral calcium supplement. Oviduct prolapse is a condition in which lower part of laying birds' oviduct turns inside out and protrudes through the vent. Suspected cases of egg bound include lack of calcium or other nutritional issues, overweight birds, unusually large or oddly shaped egg, oviduct infection, premature egg laying, lack of nesting boxes/safe place to lay the egg etc. Some researchers (Joyner, 1994 and Harrison, 1986) also reported egg bound caused by oviductal muscle malfunction in Calcium, Selenium, Vitamin E deficiencies, nutritional deficiencies, obesity and stress. Crespo et al.(2003) also recorded that young birds laying extra large eggs were prone to egg bound which happened in the present case. Egg binding without torsion or displacement of oviduct was described by Hasholt (1966). Samour (2008) opined that caesarian as an ideal treatment if both egg and hen were conservative and not responding to medical treatment. It is therefore advised to provide adequate nutritional supplement and hygienic management of young layers to prevent such condition.

\section{References}

Crespo, R and Shivprasad H.L. 2003. Developmental, metabolic and other noninfectious disorders. In: Saif YM, ed. Diseases of poultry, Iowa State press, Blackwell publishers p. 1231.

Harrison G.J. 1986. Reproductive medicine. In: Harrison GJ, Harrison LR. Clinical avian medicine and surgery. Philadelphia: WB Saunders, p. 620-623.

Hasholt J.1966. Diseases of reproductive organs of pet birds. J. Sm. Anim. Prac. 313-320.

Joy.B. and T. R. Divya. T.R. 2014. Egg bound and vent prolapse in chicken - a review of two cases. J. Vet. Med.12: 9192.

Joyner K.L.1994. Theriogenology. In: Ritchie BW, Harrison GJ, Harrison LR. Avian Medicine, Principles and application. Lake worth Fl: Wingers publishing p. 758-773.

Samour J.2008. Avian anesthesia and analgesia, egg binding/ dystocia. Avian medicine, 2nd edn, Mosby Elsevier, Elseviers Ltd, p. 525.

\section{How to cite this article:}

Laishram Kipjen Singh, W. Pipelu, G.K. Mishra, Nitish Kharayat, M.K. Patra, S.K. Singh and Kumar, H. 2017. Management of Egg Bound and Oviductal Prolapse in Duck. Int.J.Curr.Microbiol.App.Sci. 6(11): 3972-3974. doi: https://doi.org/10.20546/ijcmas.2017.611.464 